\title{
Multivariate Approach for Studying the Degradation of Perovskite Solar
} Cells.

Kettle, Jeffrey; Tyagi, Priyanka; David, Tudur; Stoichkov, Vasil

\section{Solar Energy}

DOI:

10.1016/j.solener.2019.09.054

Published: 15/11/2019

Peer reviewed version

Cyswllt i'r cyhoeddiad / Link to publication

Dyfyniad o'r fersiwn a gyhoeddwyd / Citation for published version (APA):

Kettle, J., Tyagi, P., David, T., \& Stoichkov, V. (2019). Multivariate Approach for Studying the Degradation of Perovskite Solar Cells. Solar Energy, 193, 12-19.

https://doi.org/10.1016/j.solener.2019.09.054

\footnotetext{
Hawliau Cyffredinol / General rights

Copyright and moral rights for the publications made accessible in the public portal are retained by the authors and/or other copyright owners and it is a condition of accessing publications that users recognise and abide by the legal requirements associated with these rights.

- Users may download and print one copy of any publication from the public portal for the purpose of private study or research.

- You may not further distribute the material or use it for any profit-making activity or commercial gain

- You may freely distribute the URL identifying the publication in the public portal ?
}

Take down policy

If you believe that this document breaches copyright please contact us providing details, and we will remove access to the work immediately and investigate your claim. 


\section{Multivariate Approach for Studying the Degradation of Perovskite Solar Cells}

2 Priyanka Tyagi, Tudur W. David, Vasil D. Stoichkov, Jeff Kettle*

3 School of Electronic Engineering, Bangor University, Dean St., Bangor, Gwynedd, Wales, UK,

$4 \quad *$ email; j.kettle@bangor.ac.uk

6 Abstract

7 Despite the progress in the performance of perovskite solar cells (PSCs), the absorber layer 8 degradation during prolonged exposure to multiple environmental conditions is still a major 9 issue. As the degradation depends upon many intrinsic and extrinsic factors, the need to adopt a 10 multivariate testing protocol, which provides rapid assessment of device stability, is required. To 11 do this, a Plackett Burman (PB) screening design has been used to analyze 9 different factors that 12 affect the PSC stability; including four extrinsic factors (oxygen, moisture, UV exposure and 13 temperature) and five intrinsic factors (selection of hole transport layer and electron transport 14 layer, absorber layer thickness, halide type and perovskite deposition process). This approach allows us to rank the relative severity of these factors and can be used to narrow the scope of materials and device architectures to be modified, by identifying materials and configurations, which are the most stable. The least and most stable device configurations have been identified and the success of the screening approach has been demonstrated by testing the optimized configurations under ISOS-D1 and -L2 protocols. Importantly, only 12 experiments are needed to establish the most stable combination from the 9 factors thus providing a rapid assessment.

21 Scanning electron microscopy (SEM) and X-ray diffraction (XRD) measurements of perovskite 22 absorber films have been performed in order to understand the degradation pathways and to 23 support the conclusion of PB screening technique.

24 Key words; perovskite solar cells, stability, multivariate analysis, degradation studies. 


\section{Introduction}

Perovskite solar cells (PSCs) have attracted attention due to the rapid growth in power conversion efficiencies (PCEs) over the past decade (Saliba et al., 2016; Li at al., 2016) and the possibility to integrate them in tandem configuration with traditional silicon solar cells (Sahli et al., 2018; Kanda et al., 2018). However, the poor stability remains a challenge for their commercialization. The sources of instability in PSCs are numerous and include intrinsic properties (perovskite layer composition, hole and electron transporter, electrode etc.) (Boyd et al., 2019; Christians et al., 2018a; Cao et al., 2018) and external environmental conditions such as humidity, light, temperature and thermal changes etc. Most studies on PSC stability to date have been focused on considering one or a maximum of two stress factors e.g. oxygen $\left(\mathrm{O}_{2}\right)$ (Bryant et al., 2016; Kong et al., 2016) humidity (Song et al., 2016a; Schlipf et al., 2019) or temperature (Misra et al., 2015). Although the stability study under one applied stress can provide meaningful information, it does not provide information about the likely outdoor stability during which multiple stresses are simultaneously applied. This is important for three reasons; firstly, the outdoor environment is the most likely location for deployment, so PSCs will experience multiple stresses, which will act simultaneously and vary with time (Christians et al., 2018b) Secondly, it has been observed that the degradation is accelerated due to the 'interaction' between stress factors. Thirdly, and surprisingly, it has been shown in PSCs that one stress factor can also act as the trigger to the degradation from other stresses; an example being that methyl ammonium lead iodide $\left(\mathrm{MAPbI}_{3}\right)$ absorber layer does not degrade rapidly due to illumination unless the samples are heated at above $45^{\circ} \mathrm{C}$ (Misra et al., 2015).

Some recent advancement has happened in the degradation studies of PSCs under the combined stress factors ( 2 or 3 at a time). Christians et al. have studied the degradation of triple cation based PSCs (> 1000h) under the effect of three stress factors; light (including UV-light, $\mathrm{O}_{2}$ and moisture) (Christians et al., 2018a). Domanski et al have made a very significant contribution in their study, where they have presented the impact of $\mathrm{O}_{2}$, humidity, and temperature on the operational stability of PSCs. The authors have presented a degradation study of PSCs under one stress and in the combination of multi-stress factors. They have observed that the PSCs degrade drastically in the presence of $\mathrm{O}_{2}$ and humidity (even 5\%) and were very unstable at elevated 
temperature $\left(\sim 65^{\circ} \mathrm{C}\right)$. Based on their observations, they have also proposed the stable 57 operational conditions for the PSCs (Domanski et al., 2018).

58 Another very important study on the degradation of $\mathrm{MAPbI}_{3}$ absorber layer based PSCs has been performed by Islam and coworkers where they have performed maximum power point tracking (MPPT) under continuous light illumination for $4000 \mathrm{~h}$. This study is very important as this is possibly the longest MPPT till date performed on $\mathrm{MAPbI}_{3}$ based PSCs without mixing of cations in the formulation of perovskite. The studies were performed on encapsulated devices at $30^{\circ} \mathrm{C}$ without UV filters (Islam et al., 2019).

Given the numerous and unknown range of variables that affect PSC stability, a holistic approach to study stability in PSCs would be beneficial to the community. This would enable multiple extrinsic and intrinsic factors to be modified simultaneously and their stability assessed together rather than by 'one factor at a time'. However, such a 'multi-stress' study in conjunction with device structure variation would be very time-consuming undertaking, particularly if only one factor was changed for every experiment. Therefore, we propose to use an experimental screening design from design of experiments (DOE) method, which allows us to undertake multivariate analysis of the PSC stability. Multivariate analysis techniques such as plackett burman (PB) have been widely used by the manufacturing and life science industry for process optimization, demonstrating the validity of this mathematical approach (Waśko et al., 2010; Alves et al., 2014, Briefs at al., 2013; Jain et al., 2010). Recently, our group has successfully demonstrated the applicability of PB screening in the performance optimization of field effect transistors (FETs) with 8 factors in 12 experimental runs (Gomes et al., 2019).

It can also be used in the context of PSC reliability by identifying the principle factors that impact upon stability and aid the design of the PSC to be more stable to extrinsic stress factors. The approach allows us to 1) rank which intrinsic or extrinsic degradation factor affects the stability the most and the least and 2) Identify which combination of device structure/materials yields the most stable device. To complement the statistical analysis, X-Ray diffraction (XRD) and scanning electron microscopy (SEM) measurements were performed to understand fully the degradation routes for each stress and change in device structure. 
In this work, multiple factors were studied by using the PB screening technique, which can identify the most significant degradation factors using a low number of test runs. The screening technique is capable of testing factors by requiring only $n+1$ experiments (Waśko et al., 2010; Alves et al., 2014; Briefs at al., 2013; Jain et al., 2010). This means a rapid analysis can be achieved. PB analysis utilizes a predetermined test matrix based upon the number of factors selected and the matrix used for this test was taken from Esbensen et al (Esbensen et al., 2018). Four extrinsic stress factors $\left(\mathrm{O}_{2}\right.$, humidity, UV exposure and temperature) and five intrinsic factors related to device structure (HTL and ETL, absorber layer thickness, absorber layer composition $\left(\mathrm{MAPbI}_{3}\right.$ or $\left.\mathrm{MAPbBr}_{2} \mathrm{I}\right)$ and fabrication procedure) were studied for an 'inverted' PSC structure. The PSC device structure is shown in Fig.1. For the study, two levels for each factor were considered. Based upon the number of factors selected, 12 experiments were found to be necessary, based upon the PB table.

\subsection{Design of experiments and choice of levels/factors}

99

100

101

102

103

104

105

106

107

108

109

110

111

112

113

\section{Experimental details}

Table 1 and 2 show the detailed range of stress conditions used in each experiment, where ' $L$ ' indicates the low level and ' $\mathrm{H}$ ' indicates the high level, which can be quantitative or qualitative. The ' $\mathrm{L}$ ' and the ' $\mathrm{H}$ ' levels, corresponding to each factor, were chosen based upon their impact on the stability of the PSCs sited in the previous literature. We have selected poly(3,4ethylenedioxythiophene)-poly(styrenesulfonate)(PEDOT:PSS) as 'L' level for the factor HTL as it is widely used HTL in inverted PSCs (Xiao et al., 2014; You et al., 2014) and is found very unstable compared to inorganic HTL due to the hygroscopic nature of this layer (You et al., 2016). In contrast to PEDOT:PSS, nickel oxide $\left(\mathrm{NiO}_{\mathrm{x}}\right)$ is reported as a very stable HTL in inverted PSCs (You et al., 2016; Kim et al., 2015; Zhou et al. 2018) which justified the choice of this material as the ' $\mathrm{H}$ ' level for HTL. For Perovskite absorber layer, $\mathrm{MAPbI}_{3}$ and $\mathrm{MAPbBr}_{2} \mathrm{I}$ have been chosen as the ' $\mathrm{L}$ ' and ' $\mathrm{H}$ ' levels respectively. $\mathrm{MAPbI}_{3}$ is very well studied and widely used absorber layer due to their near complete visible light absorption in the films and efficient charge extraction due to a high diffusion length for the carriers (Strabks et al., 2013; Lopez et al., 2017). This absorber layer showed high sensitivity and instability towards moisture and $\mathrm{O}_{2}$ (Bryant et al., 2016). $\mathrm{MAPbBr}_{3}$ shows better resistance towards moisture and $\mathrm{O}_{2}$ due to its 
114 crystallographic structure but at a cost of large exciton binding energy and reduced light 115 absorption, resulting in low PCE in PSCs (Lopez et al., 2017; Edri et al.; 2013). Therefore, we have selected $\mathrm{MAPbBr}_{2} \mathrm{I}$ as ' $\mathrm{H}$ ' level to compensate for the efficiency and stability (Zhao et al., 117 2014). For ETL, with and without lithium fluoride (LiF)/ [6,6]-Phenyl-C71-butyric acid methyl 118 ester $\left(\mathrm{PC}_{70} \mathrm{BM}\right)$ interface were chosen as the ' $\mathrm{H}$ ' and ' $\mathrm{L}$ ' levels because the presence of electron injection layer improves the stability and reduces hysteresis in PSCs (Wang et al., 2017). LiF was chosen because it is found to improve the efficiency of the PSCs by the doping of PCBM (Turak et al., 2017). For the fabrication steps, two-step procedure was considered as ' $\mathrm{H}$ ' level because it provides a better reproducibility as compare to the one-step procedure (' $\mathrm{L}$ ' level) ( $\mathrm{Li}$ et al., 2016; Xiao et al., 2014). Thick films were considered as the 'L' level because the devices consisting thick films were found least efficient due to the increase in recombination resistance of the absorber layer as compared to the devices with thin absorber layer $(\sim 300 \mathrm{~nm})$ ('H' level) 126 (Liu et al., 2014).

127 The selection of the extrinsic factors is quantitative. UV exposure degrades the devices faster, 128 especially in the presence of $\mathrm{O}_{2}$ (Christians et al., 2018a) so 'with UV filter' and 'without UV filter' have been taken as ' $L$ ' and ' $\mathrm{H}$ ' levels. The ' $\mathrm{L}$ ' $(0 \%)$ and ' $\mathrm{H}$ ' $(20 \%)$ levels for $\mathrm{O}_{2}$ correspond to the measurements performed in Nitrogen $\left(\mathrm{N}_{2}\right)$ and air. For humidity ' $\mathrm{L}$ ' $(<5 \%)$ and ' $\mathrm{H}$ ' $(80 \%)$ corresponds to the inert-dry conditions and ambient humidity. The ' $\mathrm{H}$ ' level of temperature is related to previous literature and the 'ISOS' standards which controls temperature at $65^{\circ} \mathrm{C}$ during accelerated testing. The ' $\mathrm{L}$ ' level was kept as $45^{\circ} \mathrm{C}$, as this is the lower temperature limit for a solar cell under 1 sun illumination (Koehl et al., 2011; Misra et al., 2015).

It is worth noting that the choice of these levels could be different for other set of experiments, which could lead different resulting conclusions. For the 2-fold PB screening technique, we are restricted to a choice of only two levels related to each factor. These levels are summarized in the table below. 
143 Table 1: Plackett-Burman (PB) table used which requires 12 experiments to study the main 144 effects of degradation to the perovskite absorber layer.

\begin{tabular}{|c|c|c|c|c|c|c|c|c|c|}
\hline & \multicolumn{4}{|c|}{ Extrinsic Factors } & \multicolumn{5}{|c|}{ Intrinsic Factors } \\
\hline Run & $\mathrm{O}_{2}$ & Humidity & UV & $\mathbf{T}$ & Halide & HTL & ETL & $\begin{array}{l}\text { Fabrication } \\
\text { Step }\end{array}$ & Thickness \\
\hline 1. & $\mathrm{~L}$ & $\mathrm{~L}$ & $\mathrm{~L}$ & $\mathrm{~L}$ & $\mathrm{~L}$ & $\mathrm{H}$ & $\mathrm{L}$ & $\mathrm{H}$ & $\mathrm{L}$ \\
\hline 2. & $\mathrm{H}$ & $\mathrm{H}$ & $\mathrm{H}$ & $\mathrm{L}$ & $\mathrm{H}$ & $\mathrm{H}$ & $\mathrm{L}$ & $\mathrm{H}$ & $\mathrm{L}$ \\
\hline 3. & $\mathrm{H}$ & $\mathrm{H}$ & $\mathrm{L}$ & $\mathrm{L}$ & $\mathrm{H}$ & $\mathrm{L}$ & $\mathrm{H}$ & $\mathrm{L}$ & $\mathrm{L}$ \\
\hline 4. & $\mathrm{H}$ & $\mathrm{L}$ & $\mathrm{H}$ & $\mathrm{L}$ & $\mathrm{L}$ & $\mathrm{L}$ & $\mathrm{H}$ & $\mathrm{H}$ & $\mathrm{H}$ \\
\hline 5. & $\mathrm{~L}$ & $\mathrm{H}$ & $\mathrm{H}$ & $\mathrm{L}$ & $\mathrm{L}$ & $\mathrm{H}$ & $\mathrm{H}$ & $\mathrm{L}$ & $\mathrm{H}$ \\
\hline 6. & $\mathrm{~L}$ & $\mathrm{~L}$ & $\mathrm{H}$ & $\mathrm{L}$ & $\mathrm{H}$ & $\mathrm{L}$ & $\mathrm{L}$ & $\mathrm{L}$ & $\mathrm{H}$ \\
\hline 7. & $\mathrm{H}$ & $\mathrm{L}$ & $\mathrm{L}$ & $\mathrm{H}$ & $\mathrm{L}$ & $\mathrm{L}$ & $\mathrm{L}$ & $\mathrm{L}$ & $\mathrm{L}$ \\
\hline 8. & $\mathrm{~L}$ & $\mathrm{H}$ & $\mathrm{L}$ & $\mathrm{H}$ & $\mathrm{H}$ & $\mathrm{L}$ & $\mathrm{L}$ & $\mathrm{H}$ & $\mathrm{H}$ \\
\hline 9. & $\mathrm{H}$ & $\mathrm{L}$ & $\mathrm{L}$ & $\mathrm{H}$ & $\mathrm{H}$ & $\mathrm{H}$ & $\mathrm{H}$ & $\mathrm{H}$ & $\mathrm{H}$ \\
\hline 10. & $\mathrm{~L}$ & $\mathrm{H}$ & $\mathrm{H}$ & $\mathrm{H}$ & $\mathrm{L}$ & $\mathrm{L}$ & $\mathrm{H}$ & $\mathrm{H}$ & $\mathrm{L}$ \\
\hline 11. & $\mathrm{H}$ & $\mathrm{H}$ & $\mathrm{H}$ & $\mathrm{H}$ & $\mathrm{L}$ & $\mathrm{H}$ & $\mathrm{L}$ & $\mathrm{L}$ & $\mathrm{H}$ \\
\hline 12. & $\mathrm{~L}$ & $\mathrm{~L}$ & $\mathrm{H}$ & $\mathrm{H}$ & $\mathrm{H}$ & $\mathrm{H}$ & $\mathrm{H}$ & $\mathrm{L}$ & $\mathrm{L}$ \\
\hline
\end{tabular}

Table 2: Definition of each low ('L') and high ('H') factor defined in table 1.

\begin{tabular}{|l|l|l|l|c|l|l|l|l|l|}
\hline & $\mathbf{O}_{2}$ & Humidity & UV & T & Halide & HTL & ETL & $\begin{array}{c}\text { Fabrication } \\
\text { Step }\end{array}$ & Thickness \\
\hline $\mathbf{L}$ & $0 \%$ & $<5 \%$ & $\begin{array}{l}\text { With UV } \\
\text { filter }\end{array}$ & $45^{\circ} \mathrm{C}$ & $\mathrm{MAPbI}_{3}$ & PEDOT:PSS & Without LiF & one-step & $500 \mathrm{~nm}$ \\
\hline $\mathbf{H}$ & $20 \%$ & $80 \%$ & $\begin{array}{l}\text { Without } \\
\text { UV filter }\end{array}$ & $65^{\circ} \mathrm{C}$ & $\mathrm{MAPbBr}_{2} \mathrm{I}$ & NiOx & With LiF & two-step & $280 \mathrm{~nm}$ \\
\hline
\end{tabular}


A 'run' in table 1 is defined as the individual experiment where the device configuration and stress factors are altered. For clarity, a table has been added to the SI (Table S1) explicitly stating the configuration and conditions used in 12 experimental runs.

\subsection{Perovskite absorber layers and Device Fabrication}

Samples for each run were fabricated on glass substrates, which were cleaned by ultra sonicating in deionized water, acetone and isopropanol for $20 \mathrm{~min}$ each, followed by $\mathrm{O}_{2}$ plasma treatment for $5 \mathrm{~min}$. The variation in sample configuration was considered by using two HTLs; PEDOT:PSS and $\mathrm{NiO}_{x}$, two compositions of perovskite $\left(\mathrm{MAPbI}_{3}, \mathrm{MAPbBr}_{2} \mathrm{I}\right.$; each with two thicknesses), perovskite layer deposition by either one-step or two-step process and including or excluding the ETL (LiF).

Shown in table 2 are the ' $L$ ' and ' $H$ ' levels used for this study. PEDOT:PSS (Ossila Al4083) was spin coated at $4000 \mathrm{rpm}$ for $40 \mathrm{~s}$ in ambient conditions and annealed at $150^{\circ} \mathrm{C}$ for 15 min. $\mathrm{NiO}_{x}$ solution was prepared by dissolving nickel nitrate hexahydrate $\left(\mathrm{Ni}\left(\mathrm{NO}_{3}\right)_{2} \cdot 6 \mathrm{H}_{2} \mathrm{O}\right)$ and ethylenediamine in 1:1 molar ratio in ethylene glycol (all from Sigma Aldrich). The solution was then left for stirring at $70^{\circ} \mathrm{C}$ for $3 \mathrm{~h}$. $\mathrm{NiO}_{\mathrm{x}}$ films were deposited at 2000rpm for $90 \mathrm{~s}$ followed by annealing at $300^{\circ} \mathrm{C}$ for $1 \mathrm{~h}$ in ambient conditions.

For the perovskite layer, three factors were varied; (i) the perovskite composition $\mathrm{MAPbI}_{3}$ or $\mathrm{MAPbBr}_{2} \mathrm{I}$, (ii) perovskite absorber layer thickness and (iii) the deposition process (one-step or two-step). The perovskite absorber layers were deposited in a $\mathrm{N}_{2}$ filled glove box. For one-step Process, The $\mathrm{MAPbI}_{3}$ solution was prepared by mixing lead iodide $\left(\mathrm{PbI}_{2}\right)$ and methylammonium iodide (MAI) in 1:1 M ratio in dimethylformamide (DMF). The solution was left on stirring for $24 \mathrm{~h}$ at room temperature and heated at $70^{\circ} \mathrm{C}$ for 10 min and during the deposition. The solution was filtered by using a $0.45 \mu \mathrm{m}$ PTFE filter. The films were deposited at $2000 \mathrm{rpm}$ and $6000 \mathrm{rpm}$ for $40 \mathrm{sec}$ with an anti-solvent (toluene) treatment in last $10 \mathrm{sec}$ of spin coating. Samples were annealed at $90^{\circ} \mathrm{C}$ for $1 \mathrm{~h}$ after the deposition. The measured thicknesses of perovskite layer were approximately $500 \mathrm{~nm}$ and $280 \mathrm{~nm}$ for $2000 \mathrm{rpm}$ and $6000 \mathrm{rpm}$ films. MAPbBr $2 \mathrm{I}$ solution was prepared by mixing $433 \mathrm{mg}$ lead bromide $\left(\mathrm{PbBr}_{2}\right)$ and $187.6 \mathrm{mg}$ MAI in $1 \mathrm{ml} \mathrm{DMF}$. The remainder of the solution preparation and film fabrication was kept the same as for $\mathrm{MAPbI}_{3}$. To deposit $\mathrm{MAPbI}_{3}$ by two-step process, separate solutions of MAI $(30 \mathrm{mg} / \mathrm{ml})$ in isopropanol and $\mathrm{PbI}_{2}(461 \mathrm{mg} / \mathrm{ml})$ in $\mathrm{DMF}$ were prepared. $\mathrm{PbI}_{2}$ solution was spin coated at 2000 
185

186

187

188

189

190

191

192

193

194

195

196

197

198

199

200

201

202

203

204

205

206

207

208

209

210

211

212

213

214

rpm and $6000 \mathrm{rpm}$ for $40 \mathrm{sec}$ on substrates from a solution heated at $70^{\circ} \mathrm{C}$ for $10 \mathrm{~min}$. Substrates were then annealed at $90^{\circ} \mathrm{C}$ for $20 \mathrm{~min}$. Subsequently, MAI was deposited at $6000 \mathrm{rpm}$ for $40 \mathrm{sec}$ and films were annealed at $90^{\circ} \mathrm{C}$ for $20 \mathrm{~min}$. Similarly, for $\mathrm{MAPbBr}_{2} \mathrm{I}$, the concentration of solution was $30 \mathrm{mg} / \mathrm{ml}$ in isopropanol for MAI and $367 \mathrm{mg} / \mathrm{ml}$ in DMF for $\mathrm{PbBr}_{2}$. The spin coating procedure was similar to that of the $\mathrm{MAPbI}_{3}$. Both the $\mathrm{PbI}_{2}$ and $\mathrm{PbBr}_{2}$ solutions were filtered using a $0.45 \mu \mathrm{m}$ PTFE filter.

After perovskite layer deposition $\mathrm{PC}_{70} \mathrm{BM}$ was deposited at $4000 \mathrm{rpm}$ for $40 \mathrm{sec}$ from a solution of $30 \mathrm{mg} / \mathrm{ml} \mathrm{PC}_{70} \mathrm{BM}$ in Chlorobenzene (CB). Finally, a layer of $\mathrm{LiF}$ was thermally evaporated at a pressure of $1 \times 10^{-6}$ torr if required. To fabricate the inverted PSCs, Indium Tin Oxide (ITO) coated glass substrate was used. The rest of the fabrication procedure was the same as mentioned above and at the top silver $(\mathrm{Ag})$ electrode was deposited at a pressure of $1 \times 10^{-6}$ torr. The active area of the devices was $1 \mathrm{~cm}^{2}$.

\subsection{Absorption Measurements and Device Characterization}

After fabrication, all samples were transferred to a UHV environmental chamber with controlled temperature and environment and optical feedthroughs. Depending on the test run, the samples were exposed to either a $\mathrm{N}_{2}$ atmosphere $(99.9 \%)$ or dry air $\left(80 \% \mathrm{~N}_{2}, 20 \% \mathrm{O}_{2}\right)$ and relative humidity was adjusted by injecting water vapor via a feed through and controlled in-situ with a calibrated sensor (lower limit is 5\%) used to maintain the relative humidity. Samples were placed onto a heated stage with sample temperature measured using a thermocouple. In all experimental runs two samples were tested under sulphur plasma class AAA lamp (Plasma-I systems $\mathrm{GmbH}$ ) at AM 1.5. For absorption studies, transmission mode measurements were conducted by using an optical fiber of $400 \mu \mathrm{m}$ core integrated with ocean optics spectrometer model HR4000. For device studies, BNC feed through allowed the samples to be connected to an external Keithley SMU. In this work, the time taken to reach $80 \%$ (T80\%) of the original value (absorption of perovskite absorber layer ) or 50\% of the final value (T50\%) were calculated and were used as the 'output responses' for each test run. To aid the analysis, a software package (Reliasoft) was used for multivariate analysis. XRD measurements were performed using a Philips X-PERT $3040 / 60$ instrument at $40 \mathrm{kV}$ voltage and $30 \mathrm{~mA}$ current with $\mathrm{CuK} \alpha$ radiation. SEM measurements have been performed using Hitachi TM3000-table top SEM. 


\section{Results and Discussion}

216

217

218

219

220

221

222

223

224

225

226

227

228

229

230

231

232

233

234

235

236

237

To analyze how changing the factors affect stability, the time taken for the samples to reach two particular lifetime points has been measured; T80\% (defined as the time to reach $80 \%$ of the initial value) and T50\% (for 50\% of initial value). A life test model was developed that uses a least square polynomial model to express the effects in terms of the stress factors or environmental conditions. Least square mean values were calculated by assuming this model of the characteristic life time as shown in eq. 1.

$$
y_{i}=f_{0}+\sum_{k=1}^{Z} f_{k} x_{n k}+\varepsilon_{n}
$$

Where $y_{i}$ represents the response, $f_{0}$ is a constant fitted parameter, $f_{1}$ to $f_{k}$ are the fitting parameters for the individual coefficients, $x_{n k}$ represents the $\mathrm{n}^{\text {th }}$ level of the $\mathrm{k}^{\text {th }}$ predictor variable and $\varepsilon_{n}$ represents the standard variance error. Multiple ' $y$ ' observations (representing the T80\% or $\mathrm{T} 50 \%$ time) can be expressed with the matrix in eq. 2 .

$$
y=\left[\begin{array}{c}
y_{1} \\
y_{2} \\
\vdots \\
y_{n}
\end{array}\right] X=\left[\begin{array}{ccccc}
1 & x_{11} & x_{12} & \cdot & x_{1 n} \\
1 & x_{21} & x_{22} & \cdot & x_{2 n} \\
: & : & \cdot & \cdot & \cdot \\
1 & x_{n 1} & x_{n 2} & \cdot & x_{n n}
\end{array}\right]
$$

The matrix $\mathrm{X}$ is denoted as design matrix containing information about the level of the predictor variable. The main effect of the experimental factors can be solved using eq. 3 (Esbensen et al., 2018)

$$
E_{X}=2\left[\sum(y+)-\sum(y-)\right] / N
$$

where $y+$ represents the high-level term, $y$-represents the low-level terms and $N$ represents the total number of experiments. The main effects are assumed to have the same variance, defined as $\sigma^{2}$, given in eq. 4 . Here $E_{X}$ represents the factors and $\mu$ is the calculated mean.

$$
\sigma^{2}=\frac{\sum\left(E_{X}-\mu\right)^{2}}{N-1}
$$

In order to identify a regression line, the standard error must be accounted. The standard error of the estimate is a measure of the accuracy of predictions and given in eq. 5 . 


$$
\sigma_{\text {est }}=\sqrt{\frac{\sum\left(Y_{\text {real }}-Y_{\text {est }}\right)^{2}}{N}}
$$

239

Where $\sigma_{\text {est }}$ is the standard error of the estimate, $Y_{\text {real }}$ is an actual value and $Y_{\text {est }}$ is an estimated value. The numerator is the sum of squared differences between the actual scores and the predicted scores. The mean squared error is $F_{M S}$ dependent on the mean squared factor, which is related to the variance of single quantity as shown in eq. 6.

$$
F_{m s}=\frac{\left(E_{X}\right)^{2}}{N}
$$

Fitted mean values are obtained from the multivariate analysis for ' $\mathrm{H}$ ' and ' $\mathrm{L}$ ' values of each factor. Figure 2 illustrates the variation of the fitted means for ' $L$ ' and ' $H$ ' levels of each factor (predictors) calculated from multivariate analysis. To calculate the fitted means, least square regression analysis has been applied to calculate the mean response values within a factorial design (2-fold PB design in our case). Fitted means can be used to identify the variation in the responses (T80\% and $\mathrm{T} 50 \%$ in this case) due to the change in the level of a particular factor (i.e. 'L' to ' $\mathrm{H}$ ' and vice versa). A systematic procedure to obtain Fig. 2 is given in SI (section S2). A higher value of fitted means for a particular level/factor is desirable as this will lead to a higher $\mathrm{T} 80 \%$ or $\mathrm{T} 50 \%$ time. However, the difference between the fitted means of the ' $\mathrm{L}$ ' and ' $\mathrm{H}$ ' level in a particular factor shows how influential this factor is in affecting the overall stability; a larger difference shows this factor has a greater impact on stability. The multivariate analysis has enabled us to determine the significance of all the stress factors. The difference between the larger and smaller value of fitted mean (FM) was calculated and plotted as a function of stress factor in the order of significance in Fig. 3(a) for T80\% and 3(b) for T50\%. From the data in Fig. 2, it is clear that for T80\% and T50\% responses, the presence of $\mathrm{O}_{2}$ has the most significant impact on the stability of the PSC, which is evidenced by the greatest difference between the fitted means of the ' $\mathrm{L}$ ' and ' $\mathrm{H}$ ' level. The exposure of the absorber layer to $\mathrm{O}_{2}$ and light leads to the formation of superoxide $\left(\mathrm{O}_{2}^{-}\right)$species, which react with the organic cation $\left(\mathrm{CH} 3 \mathrm{NH}^{+}\right)$of the photoexcited absorber layer. This mechanism is one of the root causes of degradation in the presence of $\mathrm{O}_{2}$ (Boyd et al., 2019 ; Bryant et al., 2016).

$$
4 \mathrm{CH}_{3} \mathrm{NH}_{3} \mathrm{PbI}_{3}+\mathrm{O}_{2}^{-} \rightarrow 4 \mathrm{PbI}_{2}+2 \mathrm{I}_{2}+2 \mathrm{H}_{2} \mathrm{O}+4 \mathrm{CH}_{3} \mathrm{NH}_{2}
$$


267 become a more severe factor in the device instability.

(a)

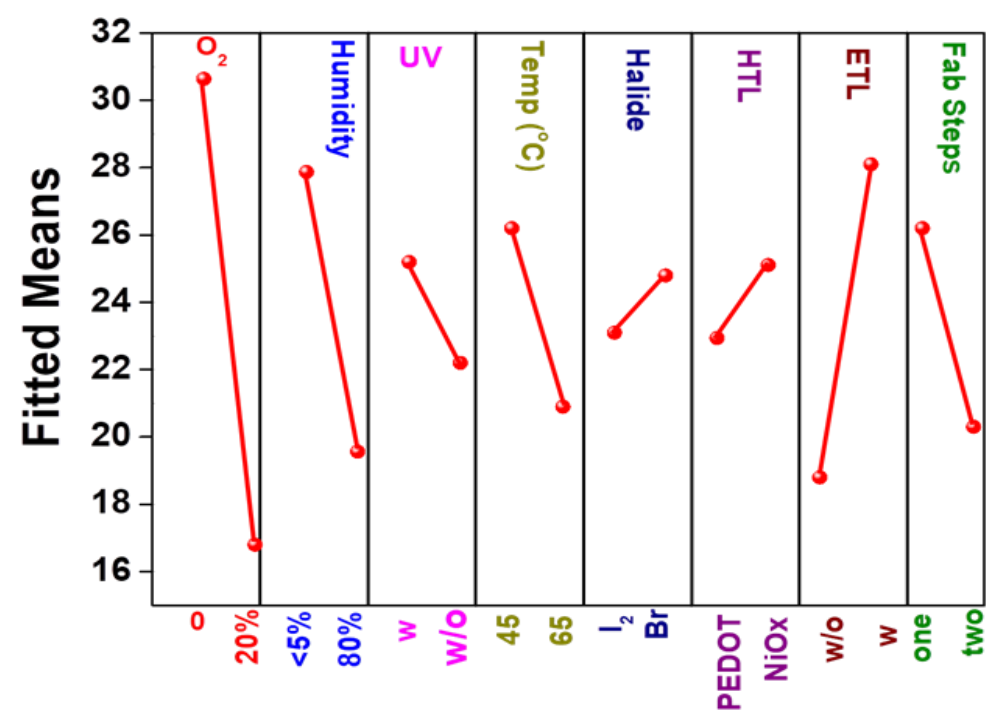

(b)

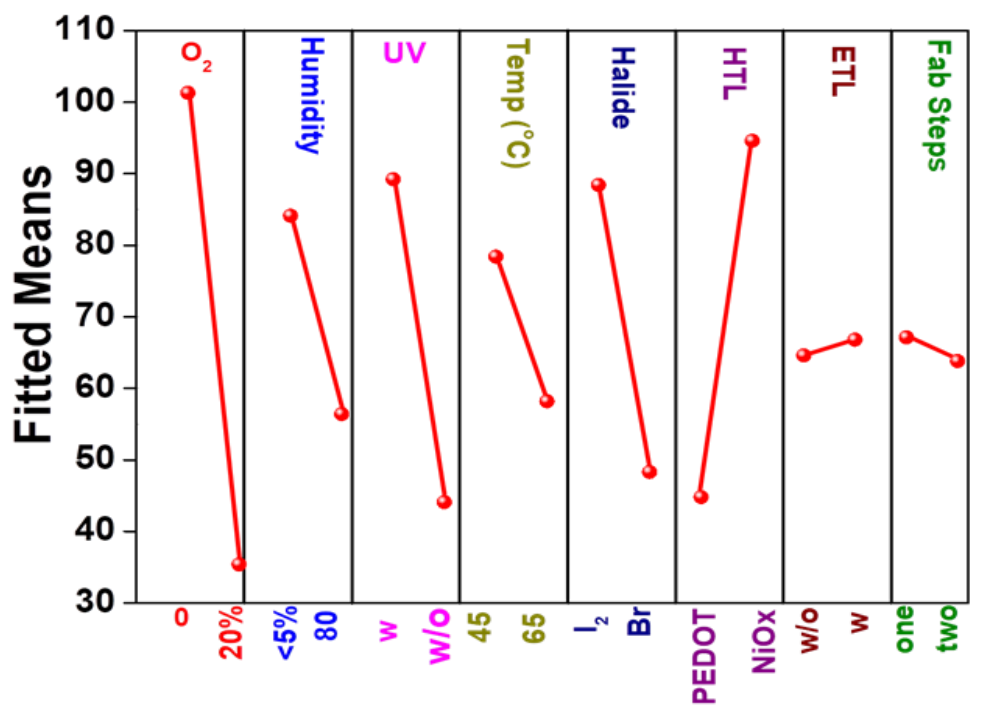

Fig. 2: Term effect plots of two-level Placket-Burman design completed using perovskite absorber layers. The results show perovskite's susceptibility to all explored main factors up to (a) $\mathbf{T} 80 \%$ and (b) $\mathbf{T} 50 \%$.

The next (second) most significant factor affecting the stability depends on whether one is 270 studying the degradation to $\mathrm{T} 80 \%$ or $\mathrm{T} 50 \%$. In the case of $\mathrm{T} 80 \%$, the second most significant 
271 factor was found to be the ETL. In this study, an inverted structure has been used, where the ETL

272 is the topmost layer. The ETL can restrict the ingress of $\mathrm{O}_{2}$ and moisture depending upon its 273 morphology (Lin et al., 2018). However, PCBM is a hydrophobic layer its alone use cannot 274 restrict the ingress of $\mathrm{O}_{2}$ and moisture through the PSC structure. It can act as a barrier for these 275 extrinsic factors by reducing gas permeation through it by the $n$-type doping (Wang et al., 2017). 276 As it is the topmost layer, it is likely to be affected by degradation first, then after the 'barrier' 277 layer is degraded; it has a lesser and lesser impact as time progresses (which is why it does not 278 feature so prominently in the T50\% data in Fig. 3).

The third most important factor to impact upon T80\% degradation time was found to be 280 the presence of humidity. It is known that perovskite absorber layer reacts with water and forms $\mathrm{CH}_{3} \mathrm{NH}_{3} \mathrm{PbI}_{3}-\mathrm{H}_{2} \mathrm{O}$ compound, which then dissociates into $\mathrm{CH}_{3} \mathrm{NH}_{3} \mathrm{I}$ and (Song et al., 2016a; Schlipf et al., 2019). This consequently leads to the degradation of perovskite absorber layer.

The next most significant factor appeared to be whether a two-step process was adopted for absorber fabrication over a one-step process. This can be explained by considering the twostep process of perovskite formation, which relies on the inter-diffusion of MAI into $\mathrm{PbI}_{2}$. However, this process is reported as a reproducible procedure, still this leaves the possibility of unreacted $\mathrm{PbI}_{2}$ in the perovskite, which was found to be the case in the present study by XRD measurements (see SI Fig. S5).

The difference in fitted means becomes smaller for the remaining factors, so it becomes more challenging to 'rank' relative severity of subsequent factors. However, it can be deduced that reducing the temperature and filtering the UV light can improve the stability. This is to be expected, as at elevated temperatures, $\mathrm{MAPbI}_{3}$ dissociates into $\mathrm{PbI}_{2}$, which is the main cause of degradation. In addition, UV radiation leads to the excitation of electrons in the absorber layer. These photo-excited electrons react with $\mathrm{O}_{2}$ to form $\mathrm{O}_{2}^{-}$and leads to the degradation of 296 perovskite absorber layer. Finally, the data shows that to achieve higher stability, replacing iodide ions with bromide ions in the absorber layer and by adopting $\mathrm{NiO}_{\mathrm{x}}$ as the $\mathrm{HTL}$ leads to greater stability, when considering the time taken to reach $\mathrm{T} 80 \%$.

In case of $\mathrm{T} 50 \%$, the general trend for enhancing the stability has changed as compared to 299 T80\% degradation. Now the order of significance of the factors affecting stability is $\mathrm{O}_{2}, \mathrm{HTL}$, 
$\mathrm{UV}$, halide type. $\mathrm{O}_{2}$ is still the most significant factor that affects degradation to T50\%. However, the selection of HTL and the filtering of UV light are now the second and third most significant factors. The impact of HTL on T50\% is significantly larger in comparison to that on T80\%.

This is because the HTL can only interact with $\mathrm{O}_{2}$ and moisture after their diffusion through the PSC structure (ETL, thick absorber layer). The HTL contributes less in initial degradation as a thick absorber layer protects it against these extrinsic factors (Boyd et al., 2019). However, the lateral diffusion of these species also takes place and does still have a minor role in the initial degradation of HTL. Among the HTLs used in this study, PEDOT: PSS has a high absorptivity of moisture, as it is water-soluble. However, under continuous illumination, its reactivity with moisture decreases due to the increase in temperature. Furthermore, PEDOT: PSS degrades itself with time and undergoes a phase separation (PEDOT rich and PSS rich phases), consequently the PEDOT rich phase becomes more susceptible towards $\mathrm{O}_{2}$-induced degradation (Norman et al., 2010). This might be contributing in still making $\mathrm{O}_{2}$ a prominent factor in $\mathrm{T} 50 \%$ degradation. The next significant factors in the order of decreasing significance were halide variation, humidity and temperature. Perovskite absorber layer in itself undergoes several changes under continuous illumination including halide segregation, ion migration, and the compositional degradation. These chemical changes become rapid in the presence of other external factors like $\mathrm{O}_{2}$ and moisture (Boyd et al., 2019; Song et al., 2016b) and become more severe with prolonged exposure. This indicates that the composition of perovskite absorber layer plays a more significant role in further $30 \%$ degradation than the initial degradation.

It has been observed from Fig. 3 that the order of significance of factors affecting the degradation to $\mathrm{T} 80 \%$ and to $\mathrm{T} 50 \%$ was different. It has been explained in the previous section how some factors such as $\mathrm{O}_{2}$, the morphology of ETL and humidity can affect the initial degradation and at a later stage, the decomposition of the absorber layer and internal degradation of HTL can dominate the process. In the case of PSCs, there are some reports where different states of degradation have been observed; initial fast degradation ('burn-in') and later slow or an almost linear regime of degradation (Domanski et al., 2018; Domanski et al., 2017; Abate et al., 2015). The degradation states were found dependent on different factors (intrinsic and extrinsic). However, it has been observed that prolonged exposure of PSCs can cause severe degradation 
(a)

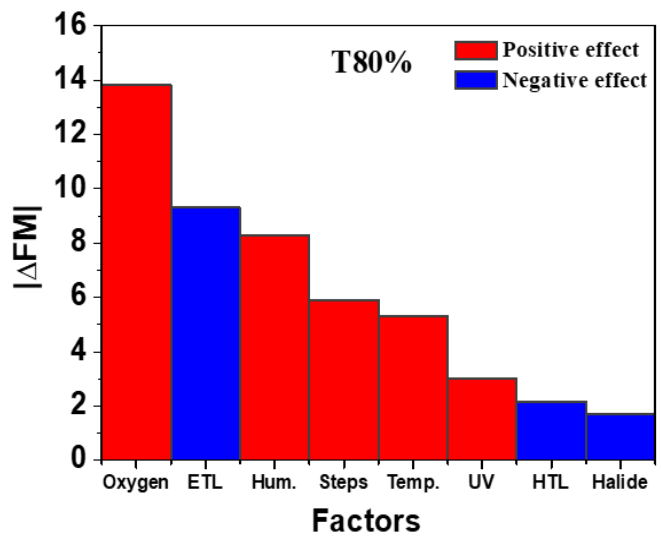

(b)

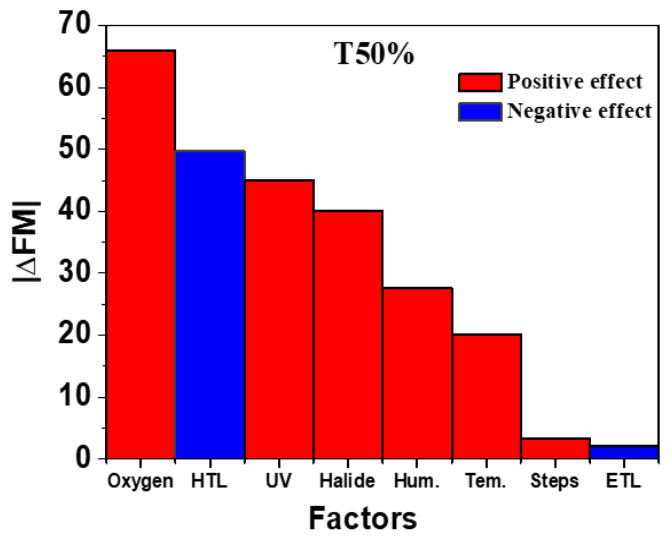

Fig. 3: The absolute difference between the highest and lowest fitted means $(|\Delta \mathrm{FM}|)$ showing the significance of factors for (a) $\mathbf{T} 80 \%$ and (b) $\mathbf{T} 50 \%$ values. A positive effect indicates that the ' $L$ ' level is preferred for higher stability.

341 To verify the studies, the most and least stable combinations were identified from PB screening 342 and compared for stability. The most stable structure was $\mathrm{NiO}_{x} / \mathrm{MAPbBr}_{2} \mathrm{I} / \mathrm{PC}_{70} \mathrm{BM} / \mathrm{LiF} / \mathrm{Ag}$ 343 (Device 'A') and the least was PEDOT:PSS/MAPbI $3 / \mathrm{PC}_{70} \mathrm{BM} / \mathrm{Ag}$ (Device 'B'). PSCs with these structures were fabricated. The PCE for Device 'A' was 5.0\% and for Device 'B' was 8.2\% with an active area of $1 \mathrm{~cm}^{2}$. The efficiency for Device ' $A$ ' is comparable to that reported with $\mathrm{MAPbBr}_{2} \mathrm{I}$ as an absorber layer (Zhao et al., 2014). The variation of photovoltaic parameters for these devices has been shown in SI (Fig. S4) averaged from 5 devices. The variation of PCE as a 
(a)

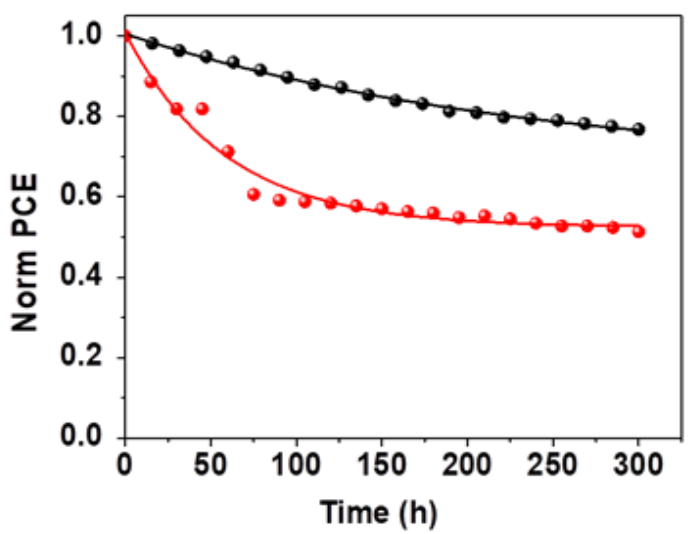

(b)

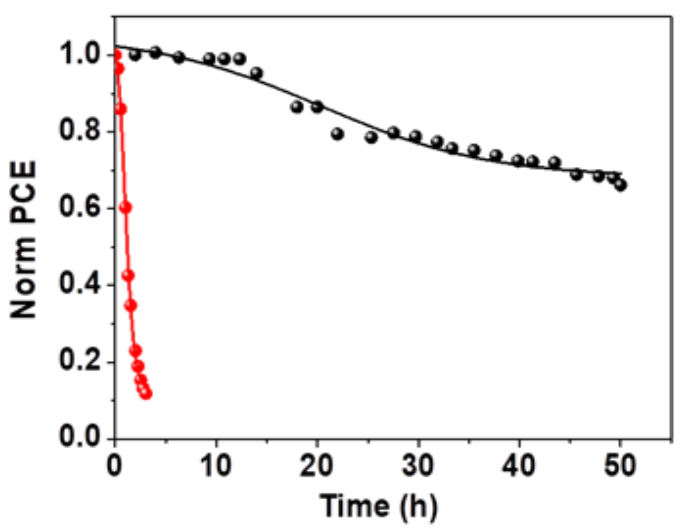

Fig. 4: Normalized power conversion efficiency as a function of time for Device ' $A$ ' (black symbol and line) and Device ' $B$ ' (red symbol and line) solar cell measured by (a) ISOS D1 (stored in the dark and ambient temperature) (b) ISOS-L2 (under continuous light exposure with controlled $65^{\circ} \mathrm{C}$ temperature).

Additional material analysis was conducted in order to investigate the degradation mechanisms. XRD and SEM measurements can be effectively used to analyze the samples upon degradation and identify the mechanism of this degradation. Here, SEM and XRD measurements were performed on the fresh and degraded films for all test runs. First, the analysis for fresh samples was performed to investigate the effect of device structure. One-step with anti-solvent treatment processed films showed no pin-holes while the two-step processed film showed small size pinholes with low density (SI Fig. S5). $\mathrm{MAPbI}_{3}$ fabricated by two-step process showed an unreacted $\mathrm{PbI}_{2}$ peak in the XRD measurements. Further, the $\mathrm{NiO}_{\mathrm{x}}$ supported better formation of perovskite film in comparison to PEDOT:PSS, which was observed by SEM and XRD measurements (SI Fig. S6). The effect of perovskite layer thickness was found more prominent on $\mathrm{MAPbBr}_{2} \mathrm{I}$ films (SI Fig. S7). 
The PB approach can also be used to deduce some of these effects of degrading the 366 samples by material analysis studies. This is somewhat difficult to do as the approach is 367 primarily for studying multivariable using minimal test runs to acquire data quickly and not for 368 detailed material studies. However, some trends can be observed to aid the understanding of 369 degradation pathways.

Figure 5 shows the SEM images of fresh and degraded samples from Run 1 (as defined in 371 Table 1). The fresh sample (Fig. 5(a)) did not show any film deformation or pinholes. The 372 degradation of the film under continuous light illumination without any additional stress factors 373 is shown in Fig. 5(b), where pin-holes of about 1um size can be observed in the samples. Fig. 3745 (c) shows the film degraded under continuous light illumination with humidity and $\mathrm{O}_{2}$ (sample 375 from run 11) and 5(d) with UV exposure (sample from run 12). The presence of UV light has 376 caused the formation of small size pinholes with a larger density, but the humidity and $\mathrm{O}_{2}$ affects 377 the films more drastically leading to very large size deformities.

The results are consistent with other reports; the exposure to humidity and $\mathrm{O}_{2}$ leads to 379 decomposition of perovskite into its constituent materials (Song et al., 2016b). $\mathrm{MAPbI}_{3}$ 380 decomposes into MAI and $\mathrm{PbI}_{2}$, which can further decompose into $\mathrm{Pb}$ and iodine (Juarez-Perez 381 et al., 2018). This would account for the large sized pinholes observed in SEM images. The 382 effect of light and UV can be explained by the reaction of photo excited electrons in perovskite 383 with $\mathrm{O}_{2}$ which form $\mathrm{O}_{2}{ }^{-}$. This $\mathrm{O}_{2}^{-}$reacts with the organic part of the perovskite layer, which leads 384 to decomposition of perovskite absorber layer. However, the results highlight the relative 385 severity and show how the presence of two or more stress factors can significantly accelerate the 386 process of degradation of perovskite absorber layer. Although the optical and morphological 387 analysis cannot guarantee a certain pattern in device degradation but it can assure valid stable 388 operational conditions. 
(a)

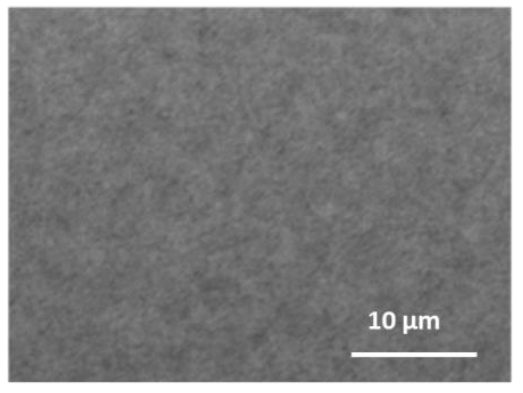

(c)

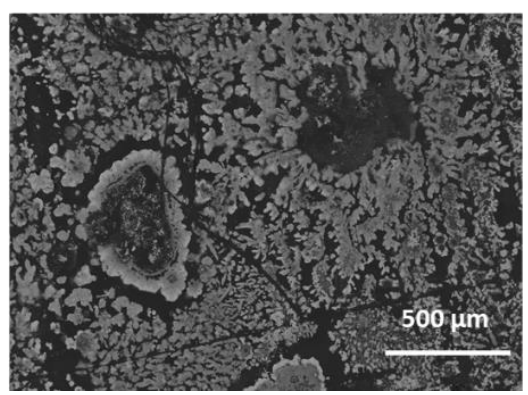

(b)

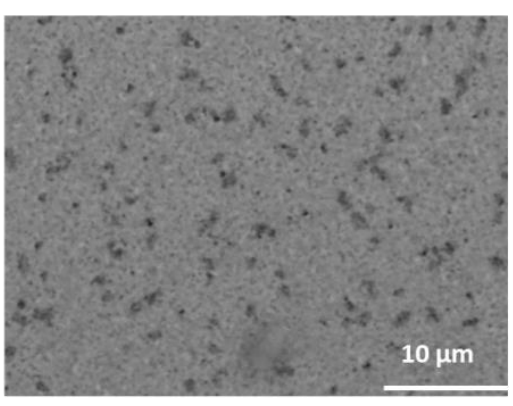

(d)

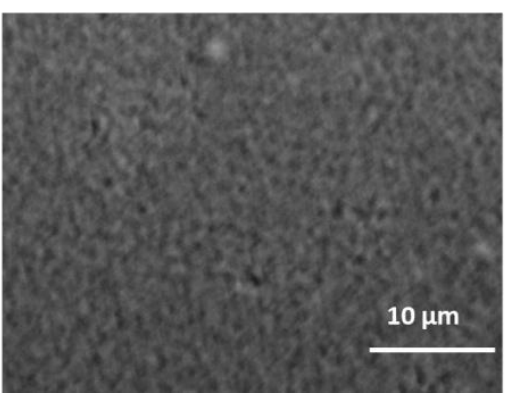

Fig. 5: SEM image of (a) fresh sample (run 1), (b) sample degraded under continuous light exposure without any extrinsic stress (sample from run 1) and (c) with humidity and $\mathrm{O}_{2}$ (sample from run 11) (d) with UV (sample from run 12).

XRD measurements were used to study the differences in degradation between $\mathrm{MAPbBr}_{2} \mathrm{I}$ and $\mathrm{MAPbI}_{3}$ samples tested during the PB screening tests. Figure 6 shows the XRD spectra of fresh 391 and degraded (a) $\mathrm{MAPbBr}_{2} \mathrm{I}$ and (b) $\mathrm{MAPbI}_{3}$ samples. In case of $\mathrm{MAPbBr}_{2} \mathrm{I}$, peaks 392 corresponding to several crystalline structures were observed in the fresh sample and are 393 highlighted in the Fig 6(a). All the crystalline peaks shifted to higher angles in the degraded 394 samples. This may be attributed to the slight decrease in d-spacing or phase change in perovskite 395 due to degradation. On the other hand, the effect of degradation on $\mathrm{MAPbI}_{3}$ is different. There is 396 no major shift in the crystalline peaks; however, an additional peak of $\mathrm{PbI}_{2}$ appeared (Fig. 6(b)). 
(a)

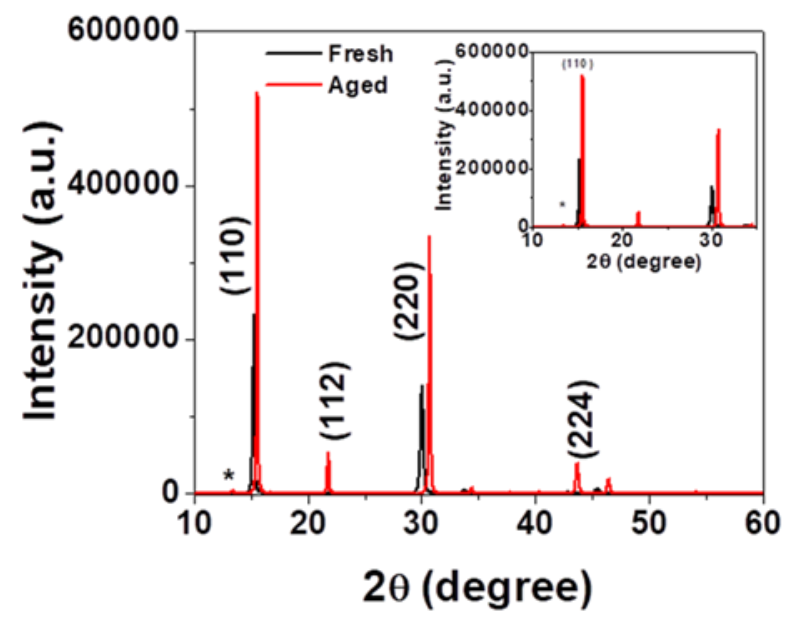

(b)

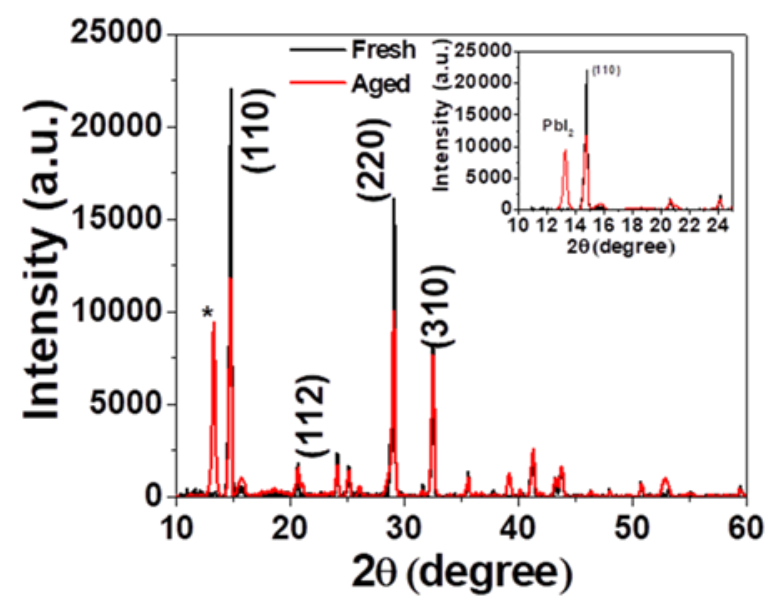

(c)

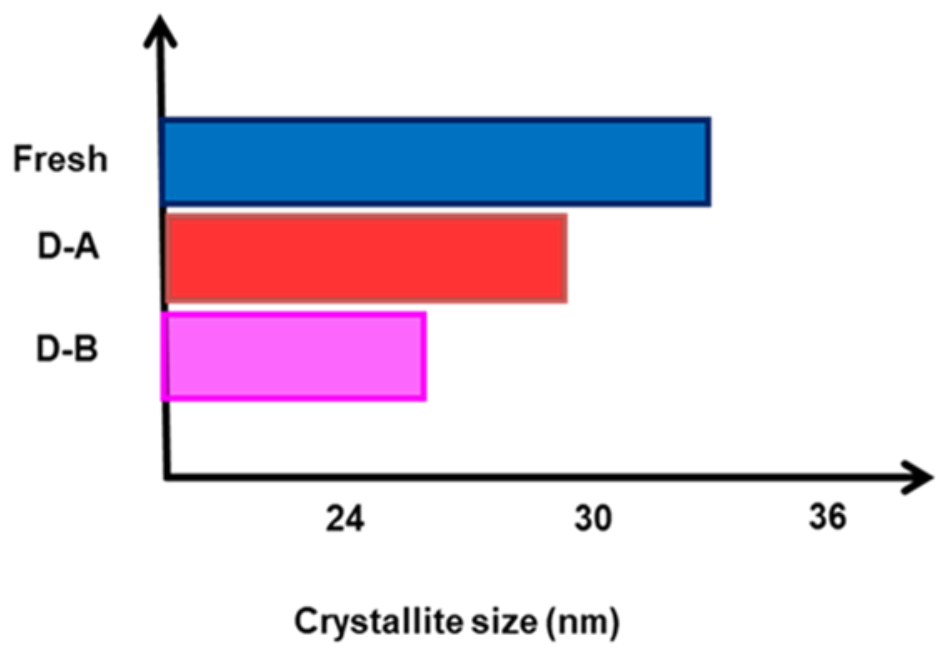

Fig. 6: XRD spectrum of fresh and degraded (under humidity and $\mathrm{O}_{2}$ ) (a) MAPbBr2I, sample from run 2 (b) MAPbI3, sample from run 11. Significant XRD peaks are marked in the figure (c) Crystallite size calculated from the XRD spectrum for fresh and degraded sample MAPbI3. D-A: degraded sample under humidity and $\mathrm{O}_{2}$ and $\mathrm{D}$-B: degraded sample under heat and $U V$.

Degradation can be quantified by crystallite size variation. The crystallite size was found to be $60 \pm 3 \mathrm{~nm}$ in case of fresh $\mathrm{MAPbBr}_{2} \mathrm{I}$ sample. We have observed a shift in (110) crystalline peak 401 of diffraction towards the higher angle. This may be attributed to loss of iodide or phase change 402 in perovskite due to degradation (Cui et al., 2016). Indeed, perovskite swelling of more than 50 403 times (in the thickness) by aqueous solutions have been observed by Song et al. (Song et al., 
2015). The variation of crystallite is shown in Fig. 6(c) for $\mathrm{MAPbI}_{3}$. The crystallite size was found to be $34 \mathrm{~nm}$ in fresh $\mathrm{MAPbI}_{3}$ sample reduces to $29 \mathrm{~nm}$ in case sample exposed to $\mathrm{O}_{2}$ and humidity and $25 \mathrm{~nm}$ in case sample exposed to UV and temperature. This reduction in crystallite size is attributed to the change in morphological changes in the perovskite films under different stresses. As we have discussed earlier, $\mathrm{MAPbI}_{3}$ decomposes into MAI and $\mathrm{PbI}_{2}$, which can also decompose into $\mathrm{Pb}$ and iodine under $\mathrm{O}_{2}$ and humidity. The perovskite layer also suffers from photo oxidation and phase change under UV and temperature. We have calculated the crystallite size of $\mathrm{PbI}_{2}$ formed under these stresses. The crystallite size of $\mathrm{PbI}_{2}$ was found to be $31 \mathrm{~nm}$ under humidity and $\mathrm{O}_{2}$ stress and $12 \mathrm{~nm}$ under $\mathrm{UV}$ and $65^{\circ} \mathrm{C}$. This may be a result of the difference in the rate of decomposition of $\mathrm{MAPbI}_{3}$ into $\mathrm{PbI}_{2}$ under both the conditions.

These results support the PB screening conclusions where we have observed that the presence of $\mathrm{O}_{2}$ and humidity has severe impact on PSC stability, within this testing range.

\section{Conclusions}

A two-fold multifactorial analysis based on Plackett -Burman screening technique has been used to screen the most and least significant factors in the degradation of PSCs. In total 9 factors have been studied under 12 test runs; four extrinsic $\left(\mathrm{O}_{2}\right.$, humidity, temperature and UV exposure) and five intrinsic (transport layers, halide type, absorber layer thickness and perovskite deposition process). To our knowledge, this is one of the most comprehensive stability studies undertaken on PSCs in terms of factors studied. The data obtained has been analyzed by multivariate analysis and the fitted means corresponding to the high and low values of each stress factor have been used to deduce the most and least significant factors. This analysis enables us to select the materials and device configuration to get the most stable PSC structure. We have fabricated the most stable and least stable PSC devices based on the conclusion made by PB screening and tested their reliability under ISOS-D1 and ISOS-L2 protocols. The time related to T80\% degradation of most stable device was measured to be 255 hours and 32 hours under ISOS-D1 and ISOS-L2 protocols. SEM and XRD measurements have been performed to find the compressive details about the morphological and structural change in perovskite layer while subjected to different stress factors for all 12 runs. 


\section{Acknowledgements}

434 The work was also supported by the Solar Photovoltaic Academic Research Consortium II 435 (SPARC II) project, gratefully funded by WEFO.

\section{Supporting Information}

437 Specification of experimental runs used and time dependent absorption measurements, Time 438 dependent absorption measurements and calculation of fitted means; absorption spectrum of 439 perovskite absorber layers, decay curve for 12 experimental runs, calculated T80\% and T50\% 440 values for each experimental run; Device performance; SEM and XRD measurements of freshly 441 prepared and aged samples.

442

443

444

445

446

447

448

449

450

451

452

453 


\section{References}

455

456

457

458

459

460

461

462

463

464

465

466

467

468

469

470

471

472

473

474

475

476

477

478

479

480

481

482

483

484

485

Abate, A., Paek, S., Giordano, F., Correa-Baena, J.-P., Saliba, M., Gao, P., Matsui, T., Ko, J., Zakeeruddin, S. M., Dahmen, K. H., Hagfeldt, A., Gratzel, M., Nazeeruddin, M. K., 2015. Silolothiophene-linked triphenylamines as stable hole transporting materials for high efficiency perovskite solar cells, Energy Environ. Sci. 8, 2946-295.

Alves, A. S., Santos, R. d., 2014. Response Surface Methodology 1.

Boyd, C. C., Cheacharoen, R., Leijtens, T., McGehee, M. D., 2019. Understanding degradation mechanisms and improving stability of perovskite photovoltaics. Chem. Rev. 119, 3418-3451.

Briefs, A. M. C. T. Experimental design and optimisation (4): Plackett-Burman designs., 2013. Anal. Methods 5, 1901.

Bryant, D., Aristidou,N., Pont,S., Sanchez-Molina,I., Chotchunangatchaval, T., Wheeler, S., Durrant, J. R. , Haque, S. A., 2016. Light and oxygen induced degradation limits the operational stability of methylammonium lead triiodide perovskite solar cells. Energy Environ. Sci. 9, 16551660 .

Cao, J., Wu, B., Chen, R. Wu, Y., Hui, Y., Mao, B.-W., Efficient, hysteresis-free and stable perovskite solar cells with $\mathrm{ZnO}$ as electron transport layer; effect of surface passivation., 2018. Adv. Mater. 30, 1705596 (1-9).

Christians, J. A., Schulz, P., Tinkham, J. S., Schloemer, T. H., Harvey, S. P., Tremolet de Villers, B. j., Spellinger, A., Berry, J. J., Luther, J. M., 2018a. Tailored interfaces of unencapsulated perovskite solar cells for $>1,000$ hour operational stability. Nat. Energy 3, 68-74.

Christians, J. A., Habisreutinger, S. N., Berry, J. J., Luther, J. M., 2018b. Stability in perovskite photovoltaics: a paradigm for newfangled technologies. ACS Energy Lett. 3, 2136-2134.

Cui, D., Yang, Z., Ren, X., Liu, Y., Wei, Q., Fan, H., Zeng, J., Liu, S., 2016. Color-Tuned perovskite films prepared for efficient solar cell applications. J. Phycs. Chem. C 120, 42-47.

Domanski, K., Roose, B., Matsui, T., Saliba, M., Turren-Cruz, S.- H., Correa-Baena, J. -P., Carmona, C. R., Richardson, Foster, J. M., Angelis, F. D., Ball, J. M., Petrozza, A., Mine, N., Nazeeruddin, M. K., Tress, W., Gra“tzel, M., Steiner, U., Hagfeldt, A., Abate, A., 2017. Migration of cations induces reversible performance losses over day/night cycling in perovskite solar cells. Energy Environ Sci. 10, 604-613.

Domanski, K., Alharbi, E. A., Hagfeldt, A., Grätzel, M. , Tress, W., 2018. Systematic investigation of the impact of operation conditions on the degradation behavior of perovskite solar cells. Nat. Energy 3, 61-67. 
Edri, E., Kirmayer, S., Cahen, D., Hodes, G., 2013. High open-circuit voltage solar cells based on organic-inorganic lead bromide perovskite. J. Phys. Chem. Lett. 4, 897-902.

Esbensen, K. H.' Swarbrick, B.' Westad, F.' Whitcomb, P.' Anderson, M., 2018. Multivariate data analysis: an introduction to multivariate analysis, process analytical technology and quality by design. CAMO Software AS' 6th Edition.

Gomes, T. C., Kumar, D., Fugikawa-Santos, L., Alves, N., Kettle, J., 2019. Optimization of the anodization processing for aluminum oxide gate dielectric in $\mathrm{ZnO}$ thin film transistors by multivariate analysis. ACS Comb. Sci. 21, 370-379.

Islam, M. B., Yanagida, M., Shirai, Y., Nabetani, Y., Miyano, K., 2019. Highly stable semitransparent $\mathrm{MAPbI}_{3}$ perovskite solar cells with operational output for 4000h. Sol. Energy Mater. and Sol. Cells 195, 323-329.

Jain, S. P., Singh, P. P., Javeer, S., Amin, P. D. Use of Placket-Burman statistical design to study effect of formulation variables on the release of drug from hot melt sustained release extrudates., 2010. AAPS Pharm. Sci. Tech. 11, 936-944.

Juarez-Perez, E. J., Ono, L. K., Maeda, M., Jiang,Y., Hawasha, Z., Qi, Y., 2018. Photodecomposition and thermal decomposition in methylammonium halide lead perovskites and inferred design principles to increase photovoltaic device stability. J. Mater. Chem. A 6, 9604-9612.

Kanda, H., Shibayama, N., Uzum, A., Umeyama, T., Imahori, H., Ibi, K., Seigo, I., 2018. Effect of Silicon Surface for Perovskite/Silicon Tandem Solar Cells: Flat or Textured. ACS Appl. Mater. Interfaces 10, 36016-35024.

Kim, J. H., Liang, P. W., Williams, S. T., Cho, N., Chueh, C.C., Glaz, M. S., Ginger, D. S., Jen, A. K.Y., 2015. High-Performance and environmentally stable planar heterojunction perovskite solar cells based on a solution-processed copper-doped nickel oxide hole-transporting layer. Adv. Mater. 27, 695-701.

Koehl, M., Heck, M., Wiesmeier, S., Wirth, J., 2011. Modeling of the nominal operating cell temperature based on outdoor weathering. Solar Energy Materials \& Solar Cells 95, 1638-1646.

Kong, W., Rahimi-Iman, A., Bi, G., Dai, X., Wu, H., 2016. Oxygen Intercalation Induced by Photocatalysis on the Surface of Hybrid Lead Halide Perovskites. J. Phys. Chem. C 120, 76067611.

Kuitche, J. M., Pan, R., Tamizhmani, G., 2014. Investigation of dominant failure mode(s) for field-aged crystalline silicon pv modules under desert climatic conditions. IEE J. Photov. 4, 814826. 
Li, X., Bi, D., Yi, C., Décoppet, J. D., Luo, J., Zakeeruddin, S. M., Hagfeldt, A., Grätzel, M., 2016. A vacuum flash-assisted solution process for high-efficiency large-area perovskite solar cells. Science 353, 58-62.

Lin, C.-T., Pont, S., Kim, J., Du, T., Xu, S., Li, X., Bryant, D., Mclachlan, M. A., Durrant, J. R., 2018. Passivation against oxygen and light induced degradation by the PCBM electron transport layer in planar perovskite solar cells. Sustainable Energy Fuels 2, 1686-1692.

Liu, D., Gangishetty, M. K., Kelly, T. L., 2014. Effect of $\mathrm{CH}_{3} \mathrm{NH}_{3} \mathrm{PbI}_{3}$ thickness on device efficiency in planar heterojunction perovskite solar cells. J. Mater. Chem. A 2, 19873-19881.

Lopez, C. A., Martinez-Huerta, M. V., Alvarez-Galvan, M. C., Kayser, P., Gant, P., CastellanosGomez, A., Fernandez-Diaz, M. T., Fauth, F., Alonso, J. A., 2017. Elucidating the methylammonium (MA) conformation in $\mathrm{MAPbBr}_{3}$ perovskite with application in solar cells. Inorg. Chem. 56, 14214-14219.

Misra, R. K. , Aharon, S., Li, B. , Mogilyansky, D. , Visoly-Fisher, I. , Etgar, L., Katz, E. A., 2015. Temperature and component-dependent degradation of perovskite photovoltaic materials under concentrated sunlight. J. Phys. Chem. Lett. 6, 326-330.

Norman, K., Madsen, M. V., Gevorgyan, S. A., Krebs, F. C., 2010. Degradation patterns in water and oxygen of an inverted polymer solar cell. J. Am. Chem. Soc. 132, 16883-16892.

Saliba, M., Matsui, T., Seo, J. Y., Domanski, K., Correa-Baena, J. P., Nazeeruddin, M. K., Zakeeruddin, S. M., Tress, W., Abate, A., Hagfeldt, A., Grätzel, M., 2016. Cesium-containing triple cation perovskite solar cells: improved stability, reproducibility and high efficiency. Energy Environ. Sci. 9, 1989-1997.

Sahli, F., Werner, J., Kamino, B. A., Brauninger, M., Monnard, R., Salomon, B. P., Barraud, L., Ding, L., Leon, J. J. D., Sacchetto. D., Canttaneo, G., Despeisse, M., Boccard, M., Nicolay, S., Jeangros, Q., Niesen, B., Ballif, C., 2018. Fully textured monolithic perovskite/silicon tandem solar cells with $25.2 \%$ power conversion efficiency. Nat. Mater. 17, 820-826.

Schlipf, J., Hu, Y., Pratap, S., Biebmann, L., Hohn, N., Porcar, L., Bein, T., Docampo, P., Muller-Buschbaum, P., 2019. Shedding light on the moisture stability of $3 \mathrm{~d} / 2 \mathrm{~d}$ hybrid perovskite heterojunction thin films. ACS Appl. Energy Mater. 2, 1011-1018.

Song, Y., Lyi, N., Hoshide, T., Ozawa, T. C., Ebina, Y., Ma, R., Miyamoto, N., Sasaki, T., 2015. Accordion-like swelling of layered perovskite crystals via massive permeation of aqueoussolutions into 2D oxide galleries. Chem. Commun. 51, 17068-17071.

Song, Z., Abate, A., Watthage, S. C., Liyanage, G. K., Phillips ,A. B., Steiner, U., Graetzel, M., Heben, M. J., 2016a. Perovskite solar cell stability in humid air: partially reversible phase transitions in the $\mathrm{PBI}_{2}-\mathrm{CH}_{3} \mathrm{NH}_{3} \mathrm{I}-\mathrm{H}_{2} \mathrm{O}$ system. Adv. Energy Mater. 6, 1600846. 
Song Z., Abate ,A., Watthage, S.C., Liyanage, G.K., Phillips, A.B., Steiner, U., Graetzel, M., Heben, M. J., 2016b. In-situ observation of moisture-induced degradation of perovskite solar cells using laser-beam induced current. Photovoltaic Specialists Conference (PVSC), 1202-1206.

Strabks, S. D., Eperon, G. E., Grancini, G., Menelaou, C., Alcocer, M. J. P. , Leijtens, T., Herz, L. M., Petrozza, A., Snaith, H. J., 2013. Electron-hole diffusion lengths exceeding 1 micrometer in an organometal trihalide perovskite absorber. Science 342, 341-344.

Turak, A., Zgierski, M. Z., Dharma-Wardana, M. W. C., 2017. LiF doping of C60 studied with Xray photoemission Shake-Up Analysis. ECS J. Solid State Sci. Technol. 6, M3116-M3121.

Wang, Y., Dong, S., Miao, Y., Li, D., Qin, W., Cao, H., Yang, L., Li, L., Yin, S., 2017. BCP as additive for solution-processed PCBM electron transport layer in efficient planar heterojunction perovskite solar cells. IEEE J. Photov. 7, 550-557.

Waśko, A, Kordowska-Wiater, M., Podlesny, M., Polak-Berecka, M., Targonski, Z., KubikKomar, A., 2010. The Plackett-Burman design in optimization of media components for biomass production of Lactobacillus rhamnosus OXY. Acta Biol. Hung. 61, 344-355.

Xiao, Z.' Bi, C.' Shao, Y.' Dong, Q.' Wang, Q.' Yuan, Y.' Wang, C.' Gao, Y.' Huang, J., 2014. Efficient, high yield perovskite photovoltaic devices grown by interdiffusion of solutionprocessed precursor stacking layers. Energy Environ. Sci. 7, 2619-2623.

You, J.' Yang, Y.' Hong, Z.' Song, T.-B.' Meng, L.' Liu, Y.' Jiang, C.' Zhou, H.' Chang W.-H.' Li, G.' Yang, Y., 2014. Moisture assisted perovskite film growth for high performance solar cells. Appl. Phys. Lett. 105, 183902.

You, J.' Meng, L.' Song, T.-B., Guo, T.-F., Yang, Y(M.).' Chang, W.-H., Hong, Z.' Chen, H.' Zhou, H.' Chen, Q.' Liu, Y.' Marco, N. D.' Yang, Y., 2016. Improved air stability of perovskite solar cells via solution-processed metal oxide transport layers. Nat. Nanotech. 11, 75-81.

Zhao, Y., Nardes, A. M., Zhu, K., 2014.Mesoporous perovskite solar cells: Material composition, charge-carrier dynamics, and device characteristics. Faraday, Discuss. 176, 301.

Zhou, Y., Yin, X., Luo, Q., Zhao, X., Zhou, D., Han, J., Hao, F., Tai, M., Li, J., Liu, P., Jiang, K., Lin, H., 2018. Efficiently improving the stability of inverted perovskite solar cells by employing polyethylenimine-modified carbon nanotubes as electrodes. ACS Appl. Mater. Interfaces 10, 31384-31393. 